\title{
Characterization of Lambda cysB and of Two Derivatives Carrying cys $B$ Amber Mutations
}

\author{
By D. M. MASCARENHAS† AND M. D. YUDKIN* \\ Microbiology Unit, Department of Biochemistry, South Parks Road, Oxford OX13QU
}

(Received 12 November 1979)

The specialized transducing phage $\lambda c y s B$ (Borck et al., 1976) was found to carry about 5 kilobases of Escherichia coli DNA. It was shown to have an intact cys $B$ gene but none of the known neighbouring genetic loci. The phage (which is known to be deficient in its sitespecific recombination functions) was shown to integrate into the chromosome of bacterial recipients at the cys $B$ locus. Excision from this site occasionally generated recombinant phages that had exchanged their $c y s B$ allele for the one originally present in the host. In this way $\lambda$ cys $B$ derivatives were prepared from lysogens of two strains carrying the amber mutations $c y s B 242$ and $c y s B 257$; these phages were proved by several tests to contain the expected cys $B$ amber mutations.

\section{INTRODUCTION}

In the enteric bacteria Salmonella typhimurium and Escherichia coli, cysteine biosynthesis is a key process in the incorporation of inorganic sulphur into organic molecules. The various steps in the pathway by which inorganic sulphate is assimilated and reduced to sulphide (a direct precursor of cysteine) are catalysed by the products of at least seven structural genes which lie scattered around the bacterial chromosome (for a review, see Smith, 1971). Expression of these genes is positively controlled by the product of the $c y_{S} B$ gene in the presence of $O$-acetyl-L-serine (Jones-Mortimer, 1968). cys $B$, which is near min 28 of the standard E. coli map, comprises a single cistron (Tully \& Yudkin, 1977), the product of which is known to be a protein (Tully \& Yudkin, 1975).

Borck et al. (1976) constructed in vitro a specialized transducing derivative of bacteriophage lambda $(\lambda c y s B)$, by replacing the central EcoRI fragment of a lambda vector that contained only two functional target sites for this endonuclease with a fragment of $E$. coli DNA. The transducing phage was selected for its ability to complement an $E$. coli cys $B$ point mutant host and was assumed to carry at least part of the cys $B$ gene. It had, however, lost the phage functions that lie between lambda sites 1 and 3 for the EcoRI endonuclease. Since these include the attP site, int, xis and $\operatorname{red} A, \lambda c y s B$ is expected to be deficient in site-specific and general recombination functions.

We now report some of the properties of this transducing phage and the preparation of two derivatives, each carrying a known $c y s B$ amber mutation.

\section{METHODS}

Bacteria and bacteriophages. All the E. coli strains used were K12 derivatives; they are described in Table 1. A non-lysogenizing mutant of phage P1 (P1 clear) was used throughout. The specialized transducing

$\dagger$ Present address: Department of Biological Sciences, Stanford University, Stanford, California 94305 , U.S.A. 


\section{Table 1. Bacterial strains}

All strains were derivatives of $E$. coli $\mathrm{K} 12$ of mating type $\mathrm{F}^{-}$.

\begin{tabular}{|c|c|c|}
\hline Strain & Genotype & Source, reference or derivation \\
\hline W3110 & Prototrophic & This laboratory \\
\hline W1485 & Prototrophic $\sup E$ & This laboratory \\
\hline MY306 & thr arg his cys $B$-sup $X^{\mathrm{del}} 100$ str $A$ & This laboratory \\
\hline HVT5 & thr arg his ton $B-t r p^{\mathrm{del}} \operatorname{str} A$ supE & H. V. Taylor \\
\hline CA275 & $l a c^{\mathrm{am}}$ trp $p^{\mathrm{am}}$ supF & M. R. Lunt \\
\hline JT32 & W3110 pyrF287 trpE9829 & Tully \& Yudkin (1977) \\
\hline JT42 & W3110 cys B242 trpE9829 & Tully \& Yudkin (1977) \\
\hline JT57 & W3110 cysB257 trpE9829 & Tully \& Yudkin (1977) \\
\hline JT61 & W 3110 cysB261 trpE9829 & Tully \& Yudkin (1977) \\
\hline JT79 & W3110 cysB279 trpE9829 & Tully \& Yudkin (1977) \\
\hline DM600 & $\mathrm{W} 3110$ cys $B-\sup X^{\mathrm{del}} 110$ & Spontaneous sup $X$ deletion \\
\hline DM601 & $\mathrm{W} 3110$ cysB-sup $X^{\mathrm{del} 1} 110 \operatorname{trpE} 9829$ & JT3 $3 \times$ P1 grown on DM 600 \\
\hline DM601E & W31 10 cysB-sup $X^{\mathrm{del} 1} 110$ trpE9829 supE & DM601 $\times$ P1 grown on HVT5 \\
\hline DM5201F & W3110 cysB279 trpE9829 supF & JT79 $\times$ P1 grown on CA 275 \\
\hline PR242 & W3110 cysB242 trpE9829 & This work \\
\hline PR257 & W3110 cysB257 trpE9829 & This work \\
\hline
\end{tabular}

phage $\lambda$ cys $B\left[\lambda \operatorname{sr} I(1-2)^{\text {del }} \operatorname{cys} B\right.$ gam $210 \operatorname{cI} 1857 \operatorname{sr} I 4^{0}$ nin $\left.5 \operatorname{sr} I 5^{\circ}\right]$ was kindly provided by Professor W. J. Brammar.

$T-M$ buffer. This contained $10 \mathrm{~mm}-\mathrm{MgSO}_{4}$ in $10 \mathrm{~mm}-\mathrm{Tris} / \mathrm{HCl} \mathrm{pH} 7 \cdot 5$.

Media. These have been described (Yudkin, 1976).

Amplification of single plaques. Single plaques were transferred from agar plates to $1 \mathrm{ml}$ T-M buffer containing $10^{7}$ cells of an overnight culture of strain W1485. This mixture was incubated at $40^{\circ} \mathrm{C}$ for $20 \mathrm{~min}$ and then diluted with $5 \mathrm{ml}$ pre-warmed $\mathrm{L}$ broth and shaken at $37^{\circ} \mathrm{C}$ for 3 to $5 \mathrm{~h}$. Cell debris was removed by centrifugation and chloroform was added.

Induction of $\lambda$ cysB lysogens. Single colonies of the lysogen were grown in $\mathrm{L}$ broth at $30^{\circ} \mathrm{C}$ to a density of about $2 \times 10^{8}$ cells ml-1. The cultures were then transferred to a water bath at $42{ }^{\circ} \mathrm{C}$ and incubated for $20 \mathrm{~min}$, and finally shaken at $37^{\circ} \mathrm{C}$ for 3 to $5 \mathrm{~h}$ until visible cell lysis occurred.

Preparation of high titre stocks of $\lambda$ cysB. A derivative of strain MY306 lysogenic for the phage was thermally induced as described above. To $500 \mathrm{ml}$ of lysate, $50 \mathrm{~g}$ polyethylene glycol 6000 and $14.6 \mathrm{~g} \mathrm{NaCl}$ were slowly added with stirring, and then the mixture was centrifuged $\left(3000 \mathrm{~g}\right.$ for $30 \mathrm{~min}$ at $\left.4{ }^{\circ} \mathrm{C}\right)$. The pellet was resuspended in $10 \mathrm{ml} \mathrm{T-M}$ buffer and caesium chloride was added to a final density of $1.48 \mathrm{~g} \mathrm{~cm}^{-3}$. This suspension was then centrifuged to equilibrium ( $21 \mathrm{~h}$ at $40000 \mathrm{rev}$. $\mathrm{min}^{-1}$ in a Spinco SW50.1 rotor at $4{ }^{\circ} \mathrm{C}$ ), the tubes were punctured and fractions were collected. Peak fractions containing the phage were pooled, dialysed against $2 \times 1000 \mathrm{vol}$. T-M buffer and then stored at $4{ }^{\circ} \mathrm{C}$. These stocks had titres ranging from $2 \times 10^{10}$ to $2 \times 10^{11} \mathrm{ml}^{-1}$.

Estimation of spontaneous curing frequencies of lysogens. This was done as described by Shimada et al. (1972).

Selection of $\lambda$ cysB lysogens. Single colonies of recipient bacteria were grown in tryptone maltose broth at $37^{\circ} \mathrm{C}$ to a density of $2 \times 10^{8}$ to $4 \times 10^{8}$ cells $\mathrm{ml}^{-1}$, then harvested by centrifugation and resuspended in T-M buffer at $10^{9}$ cells $\mathrm{ml}^{-1}$. To $0 \cdot 1 \mathrm{ml}$ of this suspension, phage were added at multiplicities of infection ranging from 0.01 to 5 plaque-forming units (p.f.u.) per bacterium. The mixtures were incubated at $33{ }^{\circ} \mathrm{C}$ for 20 to $30 \mathrm{~min}$ and then plated directly on either (i) minimal agar medium lacking cysteine (for selecting Cys $^{+}$transductants) - these plates were scored after 48 to $72 \mathrm{~h}$ at $33^{\circ} \mathrm{C}$ or (ii) tryptone agar medium seeded with $10^{9} \lambda s r I(1-2)^{\mathrm{del}} \operatorname{sr} I 3^{0} \mathrm{cI} s r I 4^{0} \operatorname{sr} I 5^{\circ}$ - these plates were incubated overnight at $33^{\circ} \mathrm{C}$ and replica-plated to maltose minimal agar plates (supplemented with the necessary amino acids) which were then incubated at $33{ }^{\circ} \mathrm{C}$ for $48 \mathrm{~h}$. Most of the non-mucoid colonies which grew up on these plates were $\lambda$ cys $B$ lysogens.

Other genetic techniques. These have been described by Yudkin (1976).

\section{RESULTS}

Size of the transducing fragment

By determining the buoyant density of $\lambda$ cys $B$ relative to that of wild-type $\lambda$ in the same caesium chloride gradient, we estimated that the $\lambda$ cys $B$ genome is about $16.5 \%$ smaller than the wild-type genome. Given the size of the lambda vector used in the construction of $\lambda$ cys $B$ 
in vitro, we calculated that the bacterial fragment in this transducing phage is about 5 kilobases in length; recent analysis with restriction endonucleases suggests a length of $5 \cdot 1 \pm 0 \cdot 2$ kilobases (D. M. Mascarenhas, unpublished results).

\section{$\lambda c y s B$ lysogens and the site of prophage integration}

$\lambda$ cys $B$ lysogens were selected either with the aid of a clear-plaque phage mutant or by transduction of a $\operatorname{cys} B$ recipient to $\mathrm{Cys}^{+}$(see Methods). Unless selection was maintained by one of these two methods $\lambda c y s B$ lysogens lost the prophage during growth in broth (the curing frequency was about $2 \times 10^{-2}$ per cell per generation as against $2 \times 10^{-6}$ for $\lambda$ att $P^{+}$ $c 1857$ lysogens). $\lambda$ cys $B$ lysogens are easy to recognize by virtue of the temperature-sensitive $c 1857$ allele on the prophage; they are also immune to superinfection with $\lambda c I$ but sensitive to $\lambda$ vir.

In a typical experiment, $\lambda \operatorname{cys} B$ generated $\mathrm{Cys}^{+}$transductants of point mutant $\operatorname{cys} B$ recipients at a frequency of about $10^{-4}$ per p.f.u. when multiplicities of infection ranging from 0.01 to 5 phage particles per bacterium were used. Not all of these transductants were lysogenic. The proportion of temperature-sensitive colonies in a transductant population varied from less than $5 \%$ to more than $95 \%$ for the different point mutants used, but was constant for a given point mutant.

During growth on tryptone agar at $41{ }^{\circ} \mathrm{C}$ these temperature-sensitive lysogens gave rise to rare non-lysogenic survivors (sensitive to superinfection with $\lambda c I$ ), some of which were $\mathrm{Cys}^{+}$. The occurrence of $\mathrm{Cys}^{+}$non-lysogenic transductants, and of heat-stable survivors of lysogenic transductants, suggested that recombination of $c y s B^{+}$from the phage on to the host could take place. One might then expect $c y s B$ recombinant phages to occur in lysates prepared from lysogenic $\lambda$ cys $B$ transductants (see below).

The site of integration of $\lambda$ cys $B$ lysogens was determined in an interrupted mating experiment. The cys $B \mathrm{HfrH}$ donor was lysogenic for $\lambda$ cys $B$ and we presumed that the time of entry of $\mathrm{Cys}^{+}$reflected the site of integration of the prophage. The results showed that this site was transferred very soon after $\operatorname{trpE}$ (in a clockwise direction of transfer) and is consequently close to, if not identical with, the chromosomal $c y s B$ locus.

$\lambda$ cys $B$ also integrated readily into a small $F^{\prime}$ factor $\left(F^{\prime} 123\right)$ that carries the region of the E. coli genome between pyrF and the $\operatorname{trp}$ genes (which includes $c y s B$ ).

\section{Transducing ability of $\lambda$ cys $B$}

A series of 62 strains with point mutations in $c y s B$ had previously been isolated in this laboratory and ordered into 16 deletion groups (Tully \& Yudkin, 1977). $\lambda$ cys $B$ was able to transduce to $\mathrm{Cys}^{+}$all 10 of the mutants from this collection that we tested, including representatives of the most $p y r F$-proximal and most $\operatorname{trp} E$-proximal deletion groups.

This phage was also able to transduce to $\mathrm{Cys}^{+}$two long $c y s B$ deletions which extend from the neighbouring gene $\sup X$ through all of the $c y s B$ gene. Cys ${ }^{+}$transductants of the strains carrying these deletions were invariably temperature-sensitive; heat-stable survivors selected from these transductants were invariably $\mathrm{Cys}^{-}$. We assume that, probably through lack of homology, $\lambda c y s B$ is unable to undergo a recombinational exchange of $c y s B$ alleles with these strains. However, because $\lambda$ cys $B$ can generate $\mathrm{Cys}^{+}$transductants from $\operatorname{cys} B$-deleted strains with which it cannot recombine, it must carry an intact $c y s B$ gene.

We showed that $\lambda$ cys $B$ does not transduce to wild-type strains carrying the mutations pyrF287 or trpE9829, and also that it does not contain a functional opp gene (Barak \& Gilvarg, 1974). (We know that the order of genes in this region of the chromosome is pyrF-cys $B$-sup $X$-opp-trpE since one of our cys $B$-sup $X$ deletions is $o p p^{+}$.) We failed in attempts to determine if $\lambda c y s B$ carries sup $X$. 


\section{Table 2. Effect of sup mutations on the transducing frequency of $\lambda$ cys $B$ and its derivatives}

The three $\lambda$ phages were used to transduce strains carrying four cysB mutations, cysB214, cysB239, cysB261 and cysB279 (Tully \& Yudkin, 1977) in $\sup ^{0}$, supD, supE or supF backgrounds. The sup strains were constructed by transducing $c y s B$ trp $E^{\mathrm{am}} 9829$ to $\mathrm{Trp}^{+}$with phage $\mathrm{P} 1$ grown on $\sup D, \sup E$ or $\sup F$ donor strains from which all trp structural genes had been deleted. The isogenic sup ${ }^{0}$ strains were constructed by performing similar transductions with phage P1 grown on a sup ${ }^{0}$ trp $^{+}$strain. The number of $\mathrm{Cys}^{+}$transductants obtained per $10^{7}$ donor $\lambda$ phages (mean of two estimations) was used to compute the ratios given.

\begin{tabular}{cccc} 
& \multicolumn{3}{c}{ Average ratio of transducing frequency } \\
Transducing phage & sup $D /$ sup & supE $/$ sup & sup $F /$ sup $^{0}$ \\
$\lambda c y s B^{+}$ & $1 \cdot 7$ & $1 \cdot 0$ & $2 \cdot 2$ \\
$\lambda c y s B 242$ & $17 \cdot 0$ & $8 \cdot 0$ & $21 \cdot 0$ \\
$\lambda c y s B 257$ & $17 \cdot 0$ & $9 \cdot 5$ & $21 \cdot 0$
\end{tabular}

\section{$\lambda$ cys $B$-amber derivatives}

Derivatives of $\lambda$ cys $B$ carrying amber mutations $c y s B 242$ and cysB257 were isolated as follows. $\lambda \operatorname{cys} B$ lysogens of JT42 and JT57 were induced and the lysates were plated on W1485. Single plaques were picked and amplified in titre (see Methods). Each isolate was then tested for transducing ability on the respective $c y s B$ parent strain. Of about 35 isolates tested in this fashion, one isolate in each case was found to be unable to transduce the parental strain to $\mathrm{Cys}^{+}$. These two phages were named $\lambda$ cysB242 and $\lambda$ cysB257, and were tentatively assumed to have acquired by recombination the cys $B$ allele originally present in the host.

In sup $^{0}$ strains $\lambda$ cysB242 and $\lambda$ cysB257 were able to transduce to Cys ${ }^{+}$(albeit at substantially reduced frequencies) all point mutations within cys $B$ tested except for the parental mutation. However, in sup strains they were able to transduce all recipients tested at frequencies comparable to those observed with $\lambda$ cys $B^{+}$. Table 2 shows that amber suppressors stimulated the recovery of transductants 8- to 22 -fold in the case of $\lambda$ cys $B 242$ and $\lambda$ cys $B 257$ but not in the case of $\lambda$ cys $B^{+}$. This is the expected result if $\lambda$ cysB242 and $\lambda$ cys $B 257$ harbour amber mutations within the $c y s B$ gene.

The two putative $c y s B$-amber phages were also able to generate $\mathrm{Cys}^{+}$transductants of the $\operatorname{cys} B$-deleted $\operatorname{supE}$ strain DM601E but not of the isogenic $s u p^{0}$ strain DM600. $\lambda \operatorname{cys} B^{+}$, on the other hand, was able to transduce the two strains at similar frequencies. As the transducing phage cannot recombine with the long cys $B$-sup $X$ deletions in these strains, $c y s B$ amber phages would be expected to supply a functional cys $B$ protein only in the suppressing recipient.

\section{Proof of the presence of the parental amber alleles in $\lambda$ cysB242 and $\lambda$ cys $B 257$}

Phage P1 was grown on a $\lambda c y s B 242$ lysogen of MY306 (a strain that carries a deletion of the whole cys $B$ gene) and used to transduce the $\sup F$ strain DM5201F to Cys ${ }^{+}$at $41^{\circ} \mathrm{C}$. Twelve transductants were purified and pooled, and phage P1 was grown on this pool of Cys $^{+}$transductants and used to transduce strain JT32 ( $\operatorname{trp} E$ cys $B^{+}$pyr $F$ sup $p^{0}$ ) to $\mathrm{Pyr}^{+}$. Some of the $\mathrm{Pyr}^{+}$transductants were Cys ${ }^{-}$. The $c y s B$ allele present in them could only have been derived, given the genetic manipulations just described, from $\lambda$ cys B242. One of these Cysisolates (which retained $\operatorname{trpE}$ ) was numbered PR242.

Strain PR257 was constructed by an exactly similar series of steps starting from a $\lambda$ cys $B 257$ lysogen of MY306.

If $\lambda$ cys $B 242$ amd $\lambda$ cys $B 257$ do carry the mutations cysB242 and cysB257, it follows that the newly constructed strains PR242 and PR257 should be identical to JT42 and JT57. We used two tests to establish whether this was so. First, the newly constructed strains, like the 
Table 3. Recombination frequency between three standard cys $B$ mutations and the cys $B$ mutations in strains JT42, PR242, JT57 and PR257

Phage P1 grown on $\operatorname{trp}^{+}$donors was used to transduce the $\operatorname{trp}$ cys $B$ recipients. The results show the percentage of $\mathrm{Cys}^{+}$colonies among the Trp ${ }^{+}$transductants (the total number of which is given in parentheses). The $t r p^{+}$donors for these experiments were constructed by transducing JT61, JT42 and JT57 to Trp ${ }^{+}$with phage P1 grown on W3110.

\begin{tabular}{lccc}
\multicolumn{3}{c}{$c y s B$ mutation in donor } \\
Recipient strain & $c y s B 26 I$ & $c y s B 242$ & $c y s B 257$ \\
JT42 & $0.9(221)$ & $0.0(101)$ & $4 \cdot 0(354)$ \\
PR242 & $0 \cdot 7(557)$ & $0.0(1142)$ & $4.0(475)$ \\
JT57 & ND & $6.8(588)$ & $0.0(913)$ \\
PR257 & ND & $6.0(1178)$ & $0.0(1107)$ \\
& ND, Not determined.
\end{tabular}

original ones, were suppressed to Cys ${ }^{+-}$by lysogeny with $\phi 80$ supF (Russell et al., 1970). Secondly, a series of three-point crosses with three cys $B$ donors showed close similarities in the recombination frequencies obtained with PR242 and JT42, on the one hand, and PR257 and JT57, on the other (Table 3).

From all these results we conclude that $\lambda$ cys $B 242$ amd $\lambda$ cys $B 257$ carry, respectively, the cys $B 242$ and $c y s B 257$ amber alleles. We have also established that parental-type $\lambda c y s B^{+}$ phages can be recovered from $\lambda c y s B 242$ and $\lambda c y s B 257$ by recombination with suitable bacterial recipients.

\section{DISCUSSION}

From its method of construction $\lambda c y s B$ is known to be deficient in its site-specific and general recombination functions. It also lacks a functional att site. Consequently, we were not surprised to find that $\lambda c y s B$ integrates at the host $c y s B$ locus. It is likely that this integration occurs via the host recombination pathways which use the homology that exists between the cys $B$ DNA fragment on the phage and the corresponding region of the chromosome. The reverse of this mechanism would lead to excision, and to the acquisition, by a certain fraction of the phage, of the host $c y s B$ allele.

Our use of this recombination mechanism to prepare $\lambda c y s B 242$ and $\lambda c y s B 257$ has given us a set of three phages, one containing the wild-type $c y_{s} B$ gene and two containing amber mutations therein. By employing these phages we have managed to identify a 39000 dalton polypeptide as the product of the E. coli cysB gene (Mascarenhas \& Yudkin, 1980).

We are greatly indebted to Professor W. J. Brammar for giving us $\lambda$ cys $B$. Some of the work described in this paper was included in a dissertation submitted by D.M.M. to the University of Oxford in partial fulfilment of the requirements for the degree of D.Phil.

\section{REFERENCES}

Barak, Z. \& Gilvarg, C. (1974). Triornithineresistant strains of Escherichia coli. Isolation, identification and genetic studies. Journal of Biological Chemistry 249, 143-148.

Borck, K., Beggs, J. D., Brammar, W. J., Hopkins, A. S. \& Murray, N. E. (1976). The construction in vitro of transducing derivatives of phage lambda. Molecular and General Genetics 146, 199 207.

Jones-Mortimer, M. C. (1968). Positive control of sulphate reduction in Escherichia coli. The nature of the pleiotropic cysteineless mutants of $E$. coli K12. Biochemical Journal 110, 597-602.
Mascarenhas, D. M. \& Yudkin, M. D. (1980). Identification of a positive regulatory protein in Escherichia coli: the product of the cysB gene. Molecular and General Genetics 177, 535-539.

Russell, R. L., Abelson, J. N., Landy, A., Gefter, M. L., BrenNer, S. \& SMITH, J. D. (1970). Duplicate genes for tyrosine transfer RNA in Escherichia coli. Journal of Molecular Biology 47, 1-13.

Shimada, K., Weisberg, R. A. \& Gottesman, M. E. (1972). Prophage lambda at unusual chromosomal locations. I. Location of the secondary attachment sites and the properties of the lysogens. Journal of Molecular Biology 63, 483-503. 
SMITH, D. A. (1971). S-amino acid metabolism and its regulation in Escherichia coli. Advances in Genetics 16, 141-165.

Tully, M. \& Yudkin, M. D. (1975). The nature of the product of the cysB gene of Escherichia coli. Molecular and General Genetics 136, 181-183.

Tully, M. \& Yudkin, M. D. (1977). Fine-structure mapping and complementation analysis of the
Escherichia coli cysB gene. Journal of Bacteriology 131, 49-56.

YUDKIN, M. D. (1976). Mutations in Escherichia coli that relieve catabolite repression of tryptophanase synthesis. Mutations distant from the tryptophanase gene. Journal of General Microbiology 92, 125-132. 